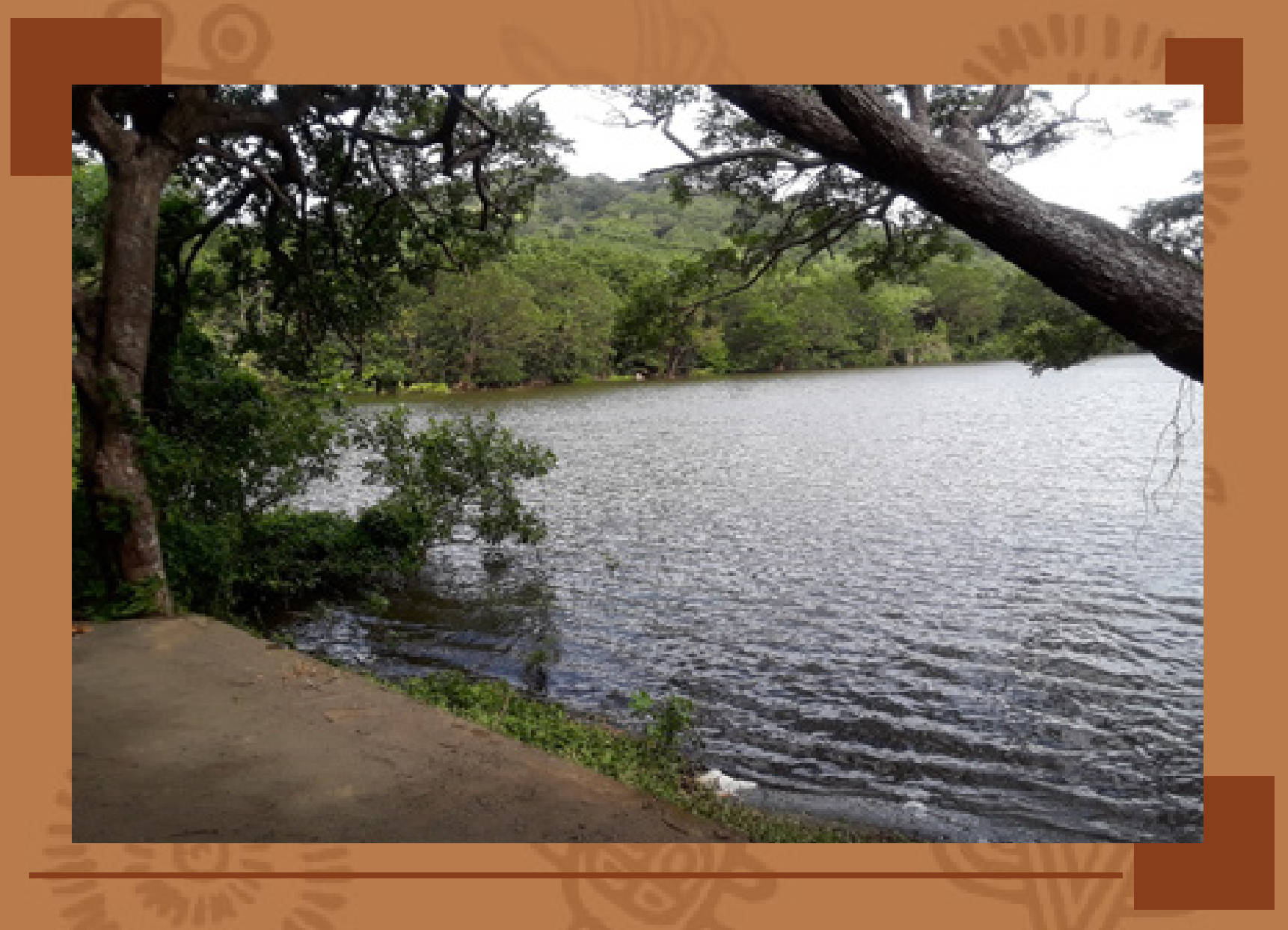

\title{
El Charco Verde: Un lugar encantado
}

Realidades Urbanas y Rurales 


\section{El Charco Verde: Un lugar encantado}

\section{El Charco Verde: An enchanted place}

Oswlin Snayder Potoy Mejía

Estudiante del cuarto año de la carrera Lengua y Literatura Hispánica de la

Universidad Nacional Autónoma de Nicaragua, UNAN- Managua.

ID Orcid: https://orcid.org/0000-0002-8795-1858

oswlin.pm.21@gmail.com

\section{Resumen}

El presente relato introduce a los lectores en la cotidianidad de las personas oriundas de la Isla de Ometepe, quienes fiel a las leyendas de sus ancestros guardaban como palabra divina cada cosa que les contaban. Ometepe, pertenece al departamento de Rivas, Nicaragua y es considerada una de las siete maravillas del mundo por la belleza de sus playas, flora, fauna y la riqueza cultural de la misma. La isla, además, tiene dos volcanes activos (El Concepción y el Maderas) uno de fuego y otro de agua; islotes y lagunas que hacen resaltar aún más su esplendor, entre ellos el asonado Charco Verde. Así mismo, el texto, nos narra una de las leyendas que tiene mayor relevancia en la Isla y que se ha extendido en algunos departamentos de Nicaragua debido a que muchos han abandonado sus tierras en busca de nuevas oportunidades de vida. Además, este trabajo, le da riqueza y recreación a la leyenda que naturalmente se conoce permitiendo situarse en el tiempo y lugar donde sucedieron los hechos.

Palabras claves: Charco Verde, brujas, misterio, Mamá Bucha, Chico Largo, encanto.

\section{Abstract}

This story introduces readers to the daily life of the people from Ometepe Island, who, faithful to the legends of their ancestors, kept everything they were told as a divine word. Ometepe, belongs to the department of Rivas, Nicaragua and is considered one of the seven wonders of the world for the beauty of its beaches, flora, fauna and its cultural richness. The island also has two active volcanoes (El Concepción and El Maderas), one of fire and the other of water; Islets and lagoons that make its splendor stand out even more, among them the asonado Charco Verde. Likewise, the text tells us one of the legends that is most relevant on the island and that has spread to some departments of Nicaragua because many have abandoned their lands in search of new life opportunities. In addition, this work gives richness and recreation to the legend that is naturally known, allowing it to be located in the time and place where the events took place.

Keywords: Charco Verde, witches, mystery, Mamá Bucha, Chico Largo, charm. 


\section{Introducción}

El Charco verde, es un cuerpo de agua que se encuentra ubicado en el municipio de San José del Sur, y tiene como límites la playa Charco verde y la Playa Bacón, desde donde se puede apreciar la Isleta El Quiste. Se cuenta que, durante la conquista española en las tierras isleñas, vivía un hombre llamado Francisco Rodríguez a quien le apodaron Chico Largo, hijo de una curandera de la comunidad llamada Úrsula. Estos comenzaron a frecuentar la laguna, después de la salida de algunos grupos españoles que colonizaron casi toda Nicaragua.

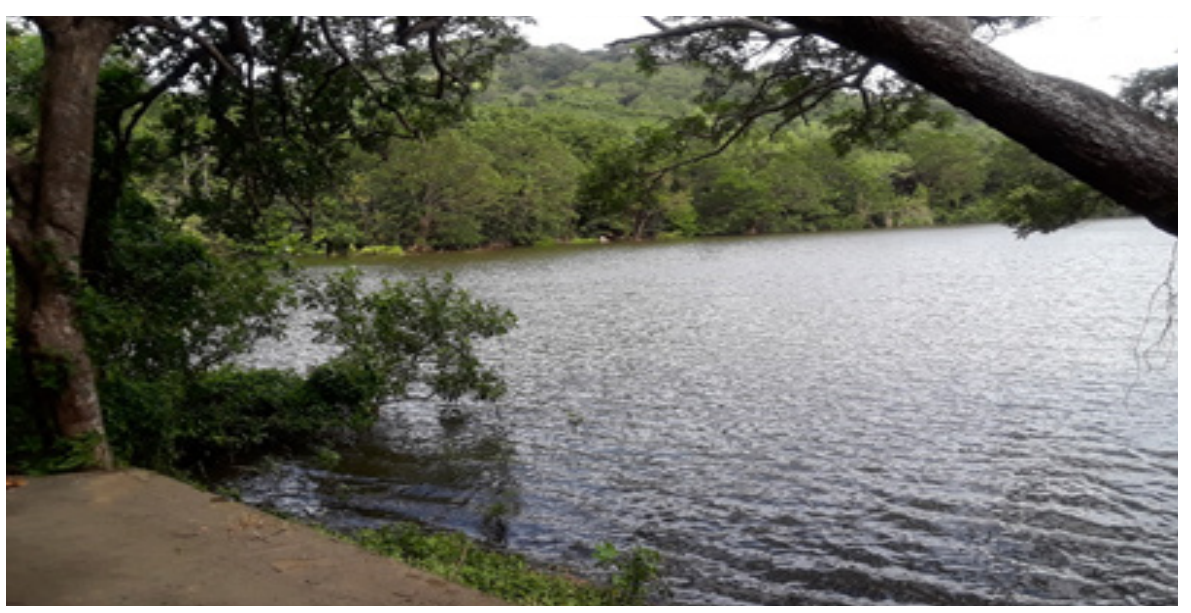

Entrada de la laguna Charco Verde, comunidad de San José del Sur, Isla de Ometepe, 2020 (Foto: Oswlin Potoy).

Doña Úrsula, mejor conocida como la Mama Bucha, era una mujer llena de costumbres, saberes y prácticas ancestrales. Su hijo, Francisco Rodríguez, retoma sus conocimientos sobre brujería, curandería y hasta reencarnación de su persona en otros animales, llevando a cabo sus rituales a orillas de la laguna Charco Verde.

En ese entonces, Ometepe estaba habitado por pocas personas, y por la complejidad para llegar al lugar era imposible que alguien lo descubriera en sus ritos.

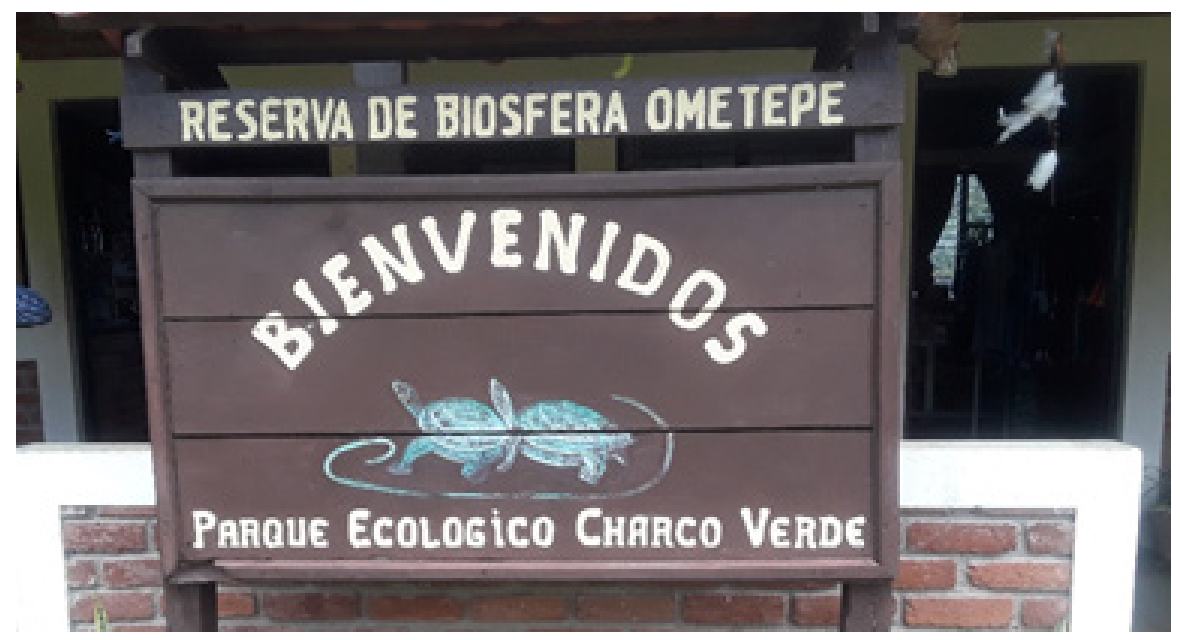

Cartel de bienvenida de la Reserva Biosfera Charco verde, comunidad de San José del Sur, Isla de Ometepe, 2020 


\section{Raíces}

Revista Nicaragüense de Antropología Año 5 No.9| 2021 Enero - Junio

Una vez, en sus andanzas Chico largo se dirigía hacia un lugar aledaño a la laguna, mejor conocido como el mirador del diablo, ahí iba convertido en venado para lograr mayor agilidad y rapidez entre los bosques donde se internaba. En el mismo lugar, había dos cazadores expertos que salían por la noche a buscar animales, algunos lo hacían para alimentarse y otros por simple pasatiempo. Francisco, nunca pensó que en el lugar estaban esos hombres, y que podían confundirlo con un animal más de la localidad.

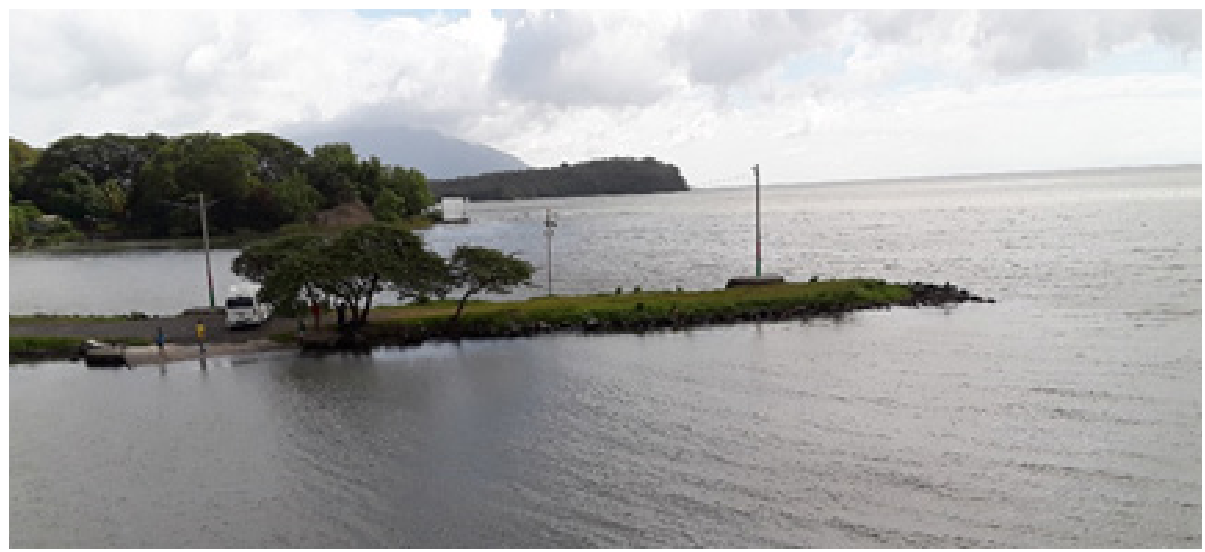

Puerto de la comunidad de San José del Sur, Isla de Ometepe, 2020, vista desde uno de los Ferris (Foto: Oswlin Potoy).

Eran pasada las doce de la noche, Chico largo se movilizaba entre los árboles del bosque, creyendo que estaba solo, haciendo ruidos, comiendo las hierbas del suelo y, seguramente, uno que otro plátano que se encontraba tirado, pues en la Isla, esta fruta crece sin necesidad de llevar un proceso riguroso de siembra. Confiado de estar en su zona territorial, es divisado a la distancia por los cazas animales, quienes haciendo uso de sus herramientas (pistola) le disparan, hiriendo gravemente una de las patas. Era la persona de Chico largo la herida, este, corrió con mucha velocidad para lograr huir de los que le habían dado un certero tiro.

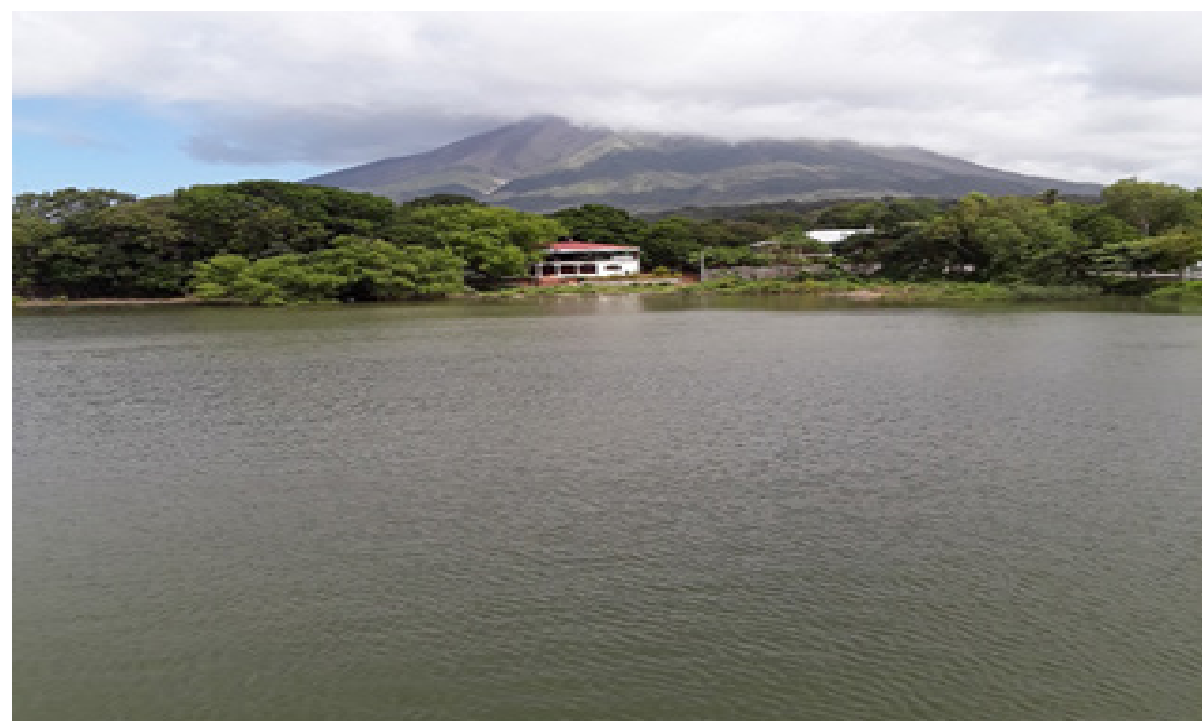

Vista del Volcán Concepción desde el Puerto San José, comunidad de San José del Sur, Isla de Ometepe, 2020 (Foto: Oswlin Potoy) 
Eran las dos de la mañana y los hombres seguían los rastros del venado, quien a su paso dejaba marcas enormes de sangre. La búsqueda se hizo cansada, pues llegaron a ver los primeros rayos del alba, eran casi las cinco de la mañana y no pudieron capturarlo.

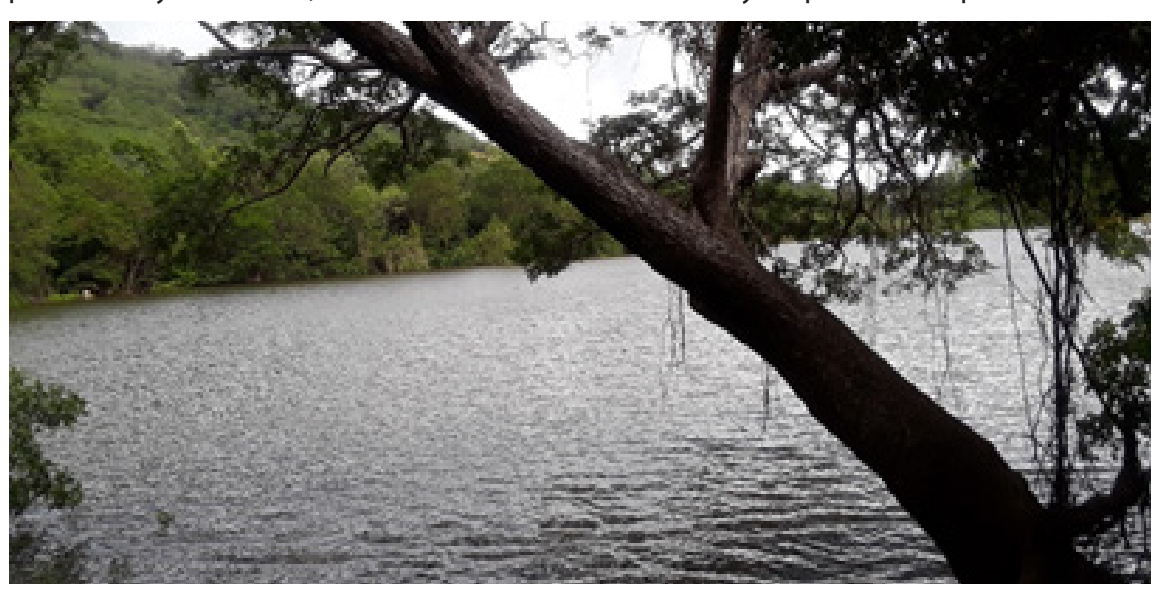

Entrada de la laguna Charco Verde, comunidad de San José del Sur, Isla de Ometepe, 2020 (Foto: Oswlin Potoy).

Ellos comenzaron a preguntarse entre sí, que pasaba, porque no pudieron atraparlo, si por su experticia ningún animal se escapaba de sus manos. Al llegar a los bordes de la laguna, las huellas del animal, comienzan a desaparecer, el ambiente se torna macabro, el cielo se volvió a poner oscuro, y un frío que congelaba hasta las mismas hojas y paralizaba el movimiento de los árboles comenzó a sentirse en el ambiente.

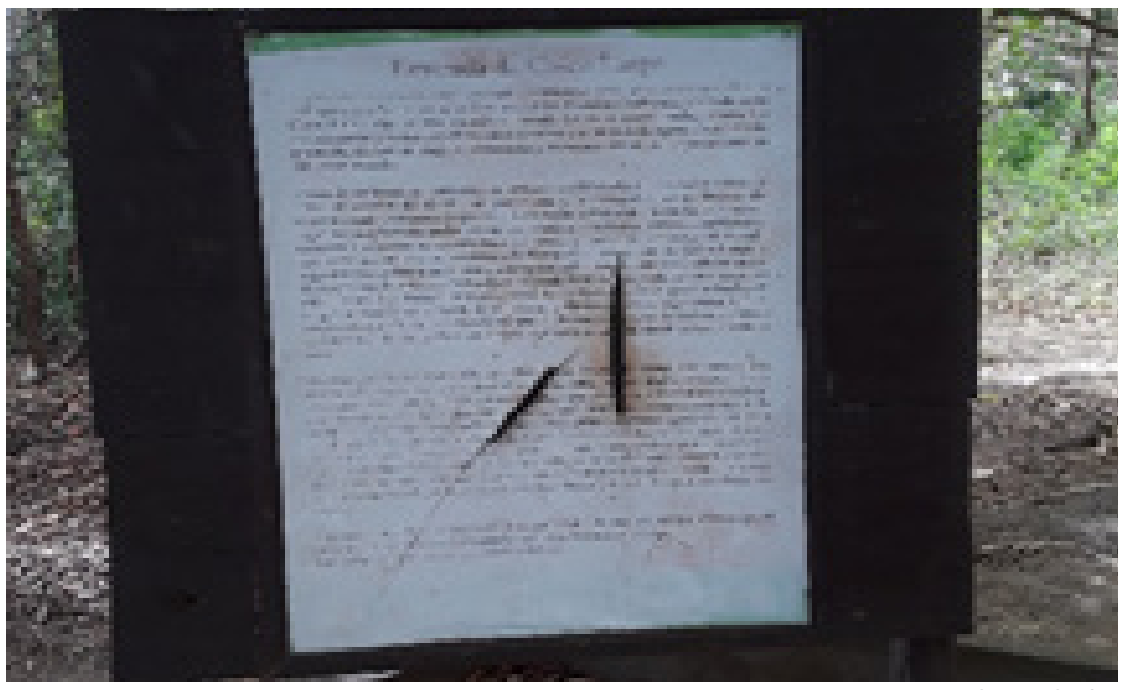

Leyenda que se encuentra en la entrada a la laguna Charco Verde, comunidad de San José del Sur, Isla de Ometepe, 2020 (Foto: Oswlin Potoy).

Chico largo, desapareció. Los hombres confundidos y sin respuesta alguna, se quedaron observando que los rastros de sangre acababan en las orillas de la laguna, y el agua que tenía un color verdoso, comenzó a mezclarse con la sangre saliente desde el fondo de la misma. 


\section{Raíces}

Revista Nicaragüense de Antropología Año 5 No.9| 2021 Enero - Junio

Se marcharon del lugar, y emprendiendo rumbo al pueblo se dispusieron a contarles.

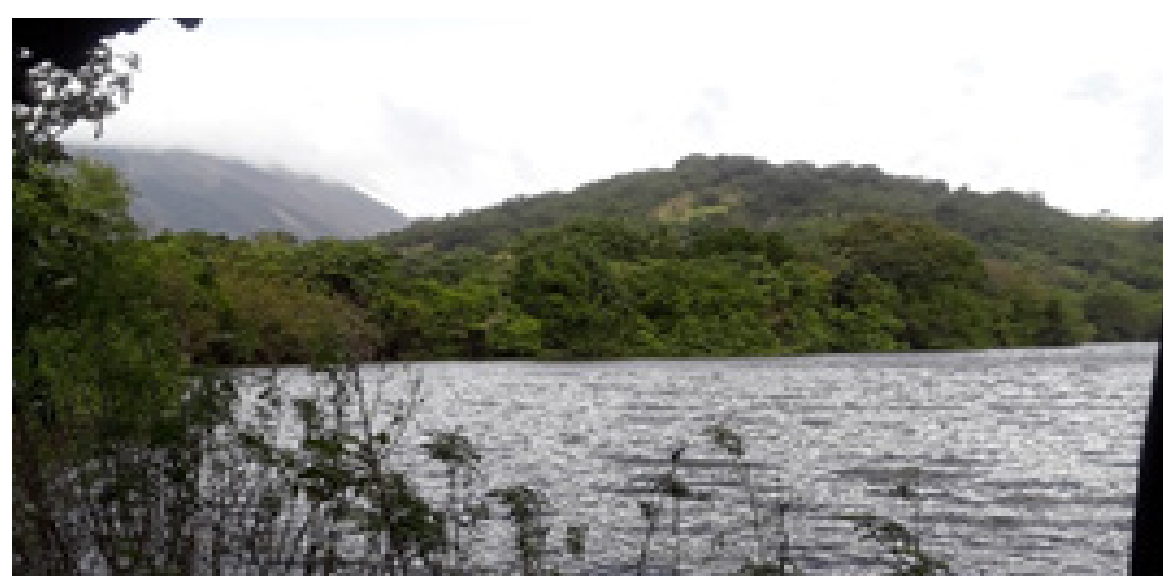

Vista de la laguna El Charco Verde, comunidad de San José del Sur, Isla de Ometepe, 2020 (Foto: Oswlin Potoy).

En el pueblo, vivían un matrimonio de ancianos de nombres Cipriano y Narcisa quienes se levantaban muy de mañana para hacer sus labores. Doña Narcisa, a quien toda la comunidad conocía como "doña Chicha", alzó sus ojos para ver a la cara a los hombres, pues era una mujer jorobada por la avanzada edad que tenía, asustada por el rostro pálido y de asombro que llevaban, tan grande era, que la señora se llenó de nervios y entre tartamudeos preguntó: - ¿qué queee que les papasa mis muchachitos? uno de ellos se quedó con la mirada perdida y en silencio, sin embargo, el otro respondió -"Un venado, un venado, le pegamos un tiro y corrimos duro, pero, cuando por fin creímos que lo habíamos agarrado a ese bandido, se desapareció entre las aguas de la laguna, allí donde decían que la mamá bucha hacía sus macumbas".

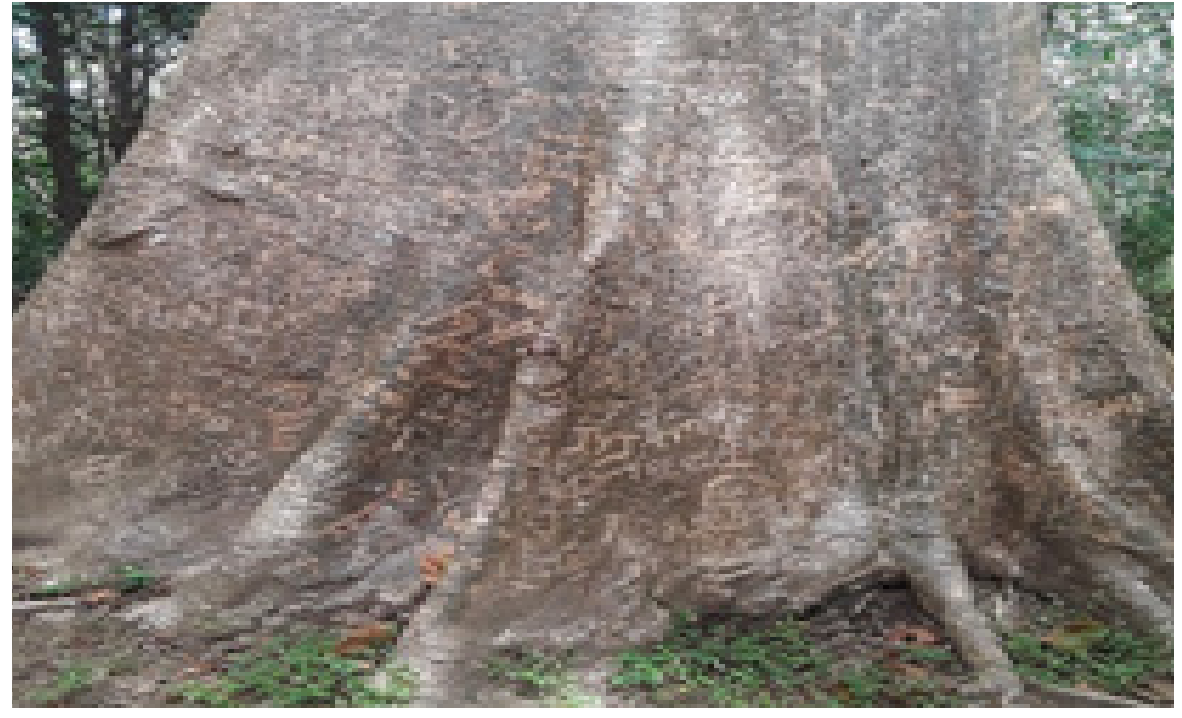

Árbol de Ceiba que se encuentra en los bordes de la laguna Charco Verde, donde los visitantes dejan escritos sus nombres, comunidad de San José del Sur, Isla de Ometepe, 2020

(Foto: Oswlin Potoy) 
La viejecilla, alarmada por lo que escucha comienza a llamar al pueblo para contarles lo acaecido y advertirles que ninguno vaya ahí, pues ese lugar es sitio del diablo.

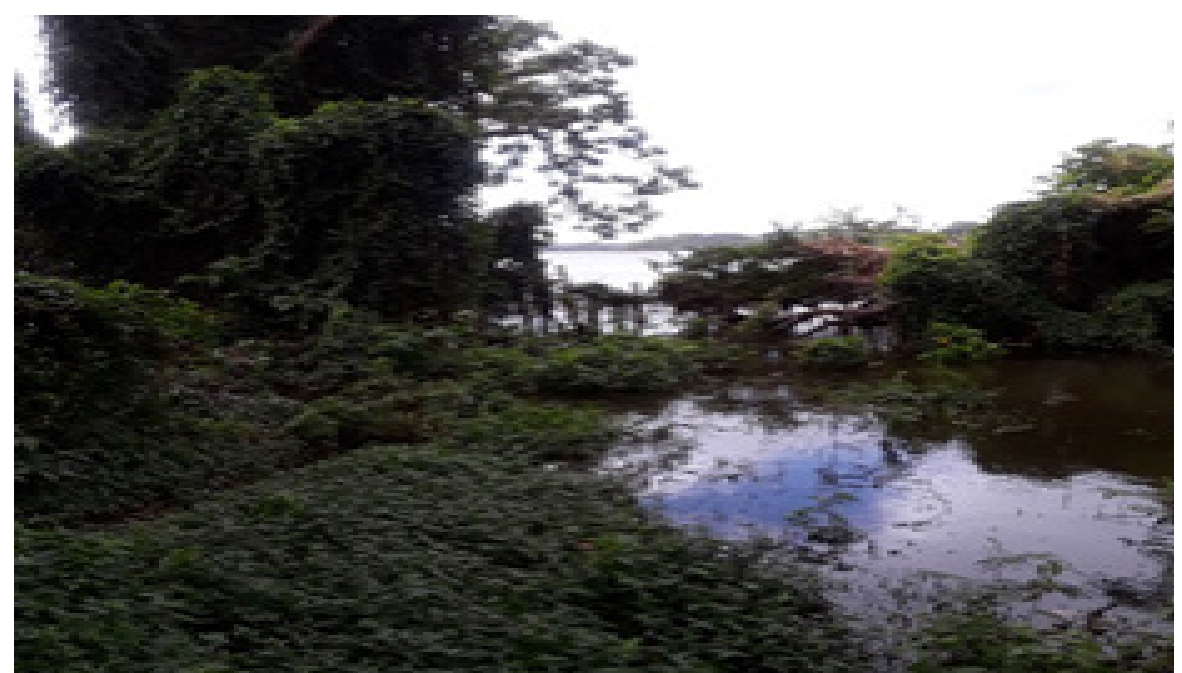

(Foto: Oswlin Potoy)

En la mañanita del siguiente día, cuentan los citadinos que diariamente iban en busca de leña, ver un tanto preocupada a la mamá Úrsula, buscando entre un saco, hojas y hierbas que utilizan para curar las heridas. Acostado en una hamaca, se lograba divisar a su hijo, quien parecía tener envuelta en trapos la pierna izquierda, más nunca asociaron el relato de los cazadores con Chico Largo. Alistaba la mama bucha su libro de oraciones y los cocimientos para poder salvarle la vida a su hijo, pues este, no podía practicar ningún rito para lograr su mejoría porque estaba herido. Días más tarde, entre el pequeño pueblo que todos se conocían y casi mantenían el número de los que habitaban comienzan a notar la ausencia de Rodríguez.

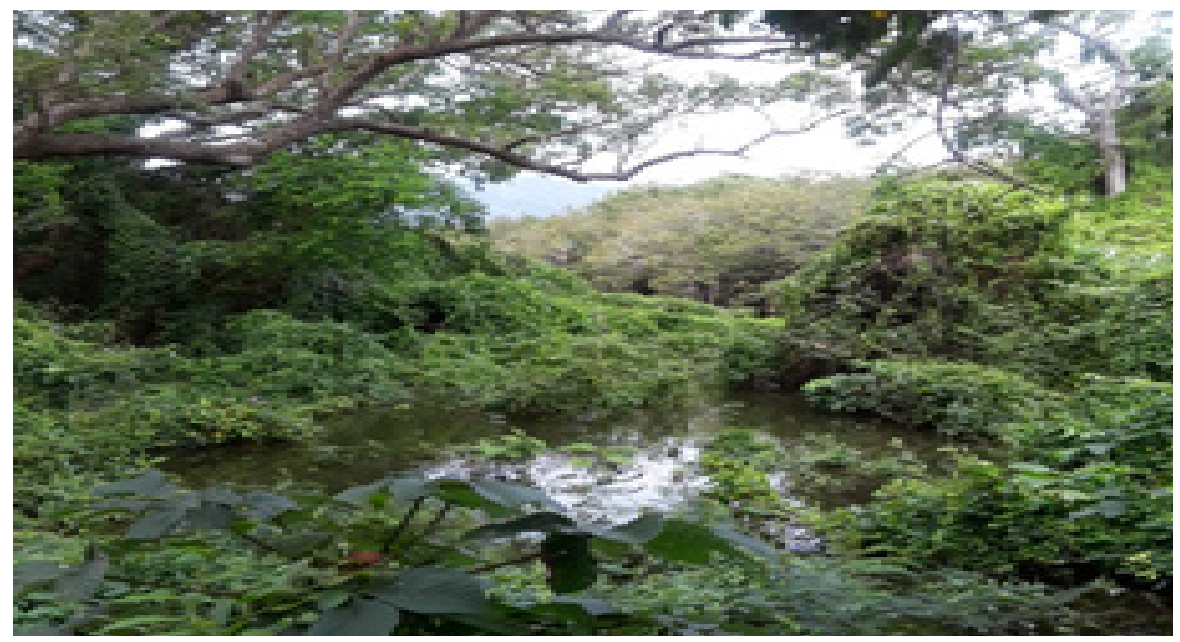

Vista del extremo izquierdo de la laguna Charco Verde, comunidad de San José del Sur, Isla de Ometepe, 2020 (Foto: Oswlin Potoy). 


\section{Raíces}

Revista Nicaragüense de Antropología Año 5 No.9| 2021 Enero - Junio

Francisco Rodríguez, murió. Mamá Úrsula, toma en sus brazos el cuerpo de su hijo, quien llora amargamente su muerte y grita tan fuerte, que casi todos se dan cuenta, parecían los mismos gritos de un ser venido del más allá. Así pasó con él toda la noche, recitando oraciones a la orilla de un fogón que les servía como luz para la casa. Tenía sus enaguas niste por el calor del fuego y tan sucias que su color blanco ya no era sino café, su pelo, canoso por la edad, estaba duro y con desperdicio que se escapó cuando buscaba entre el saco las hierbas para restablecer a su muchachito.

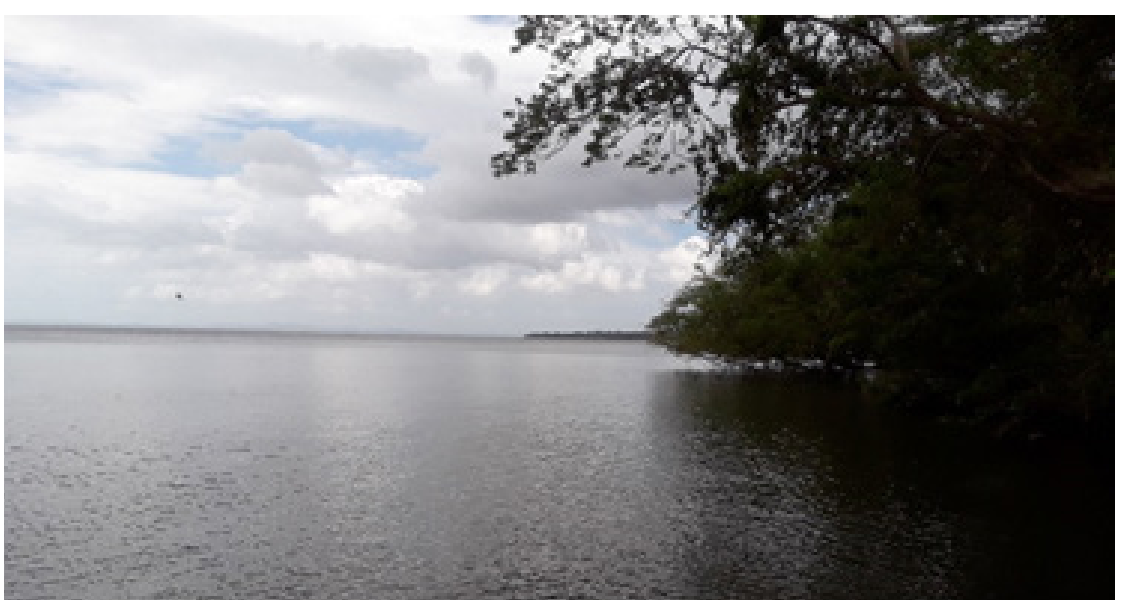

Playa Charco Verde, comunidad de San José del Sur, Isla de Ometepe, 2020 (Foto: Oswlin Potoy).

Eran la una de la mañana y guardando el secreto de la gente salía de su casa rumbo a la laguna, teniendo únicamente la iluminación de la luna, llevando en una carreta el cuerpo de su hijo, quien fue enterrado en el mismo lugar donde él hacía sus rituales.

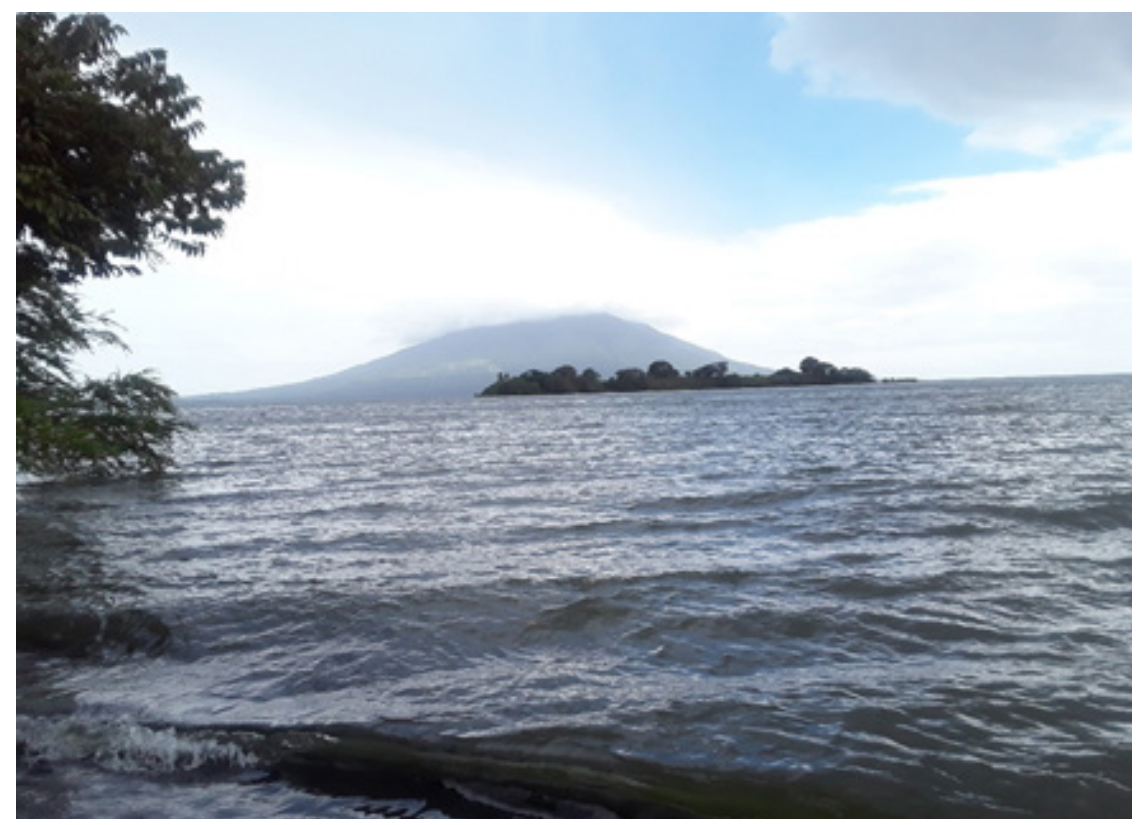

Playa Charco Verde, comunidad de San José del Sur, Isla de Ometepe, 2020 (Foto: Oswlin Potoy). 
Al cabo de diez días, la gente murmuraba sobre la ausencia del hijo de la mamá bucha. Un grupo como de setenta personas acordaron ir a la casa donde vivía Chico, y comenzaron a gritar: "Doña Úrsula, salga, queremos hablar con usted" "Mama Bucha, que hiciste a Chico Largo, lo tienes encerrado para que no se case con la hija de doña Tere", después de tantos gritos, salió la mujer, y contándoles dijo que su hijo había muerto y que fue enterrado. Ella les dijo que lo enterró en las orillas de la laguna, todos llegaron hasta ahí, y dos hombres comenzaron a cavar el lugar donde señaló la bruja, el susto de todos fue que solo encontraron las mortajas que le puso su mamá y la ropa que llevaba ese día lleno de sangre.

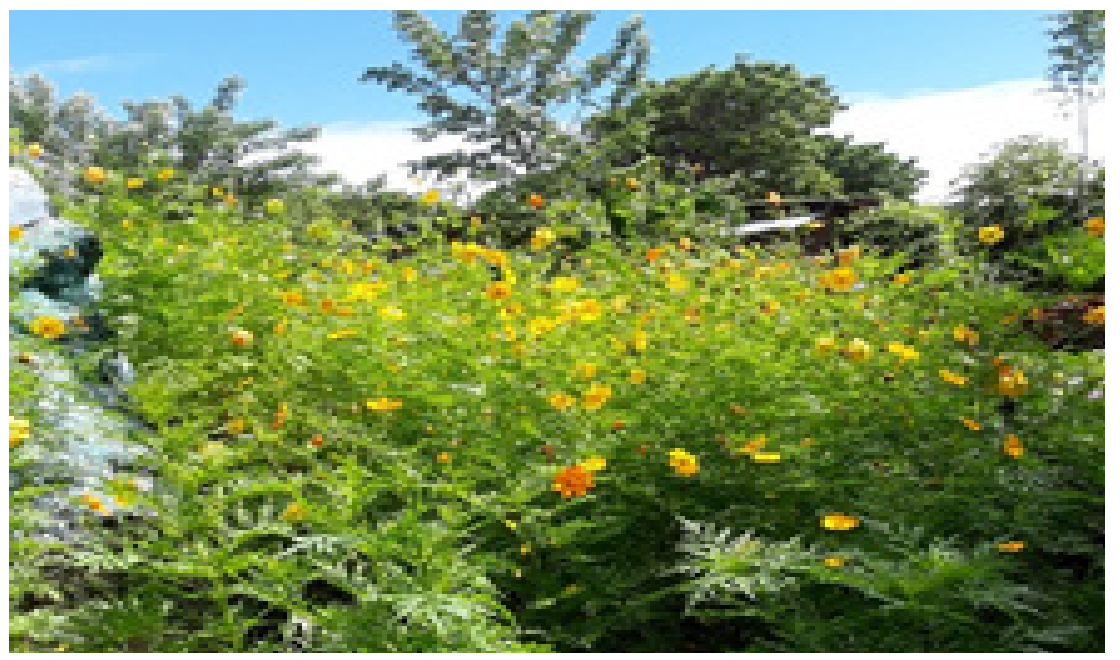

Planta que se encuentra en la entrada al parque y mariposario Charco Verde, comunidad de San José del Sur Isla de Ometepe, 2020 (Foto: Oswlin Potoy).

Todos quedaron horrorizados por lo que vieron, y decían entre ellos: "Se lo llevó el diablo". Hasta que regresaron cada uno a sus casas se acordaban de lo que contaron los hombres aquellos días. Mama Bucha en su intento frustrado de sanar a su hijo, ni siquiera pudo romper el hechizo de la reencarnación, y Francisco Rodríguez, fue sepultado mitad humano, mitad venado. Desde entonces hasta la actualidad, la gente sigue diciendo que el espíritu de Chico Largo habita en el Charco Verde, protegiendo el mundo encantado que creó para él.

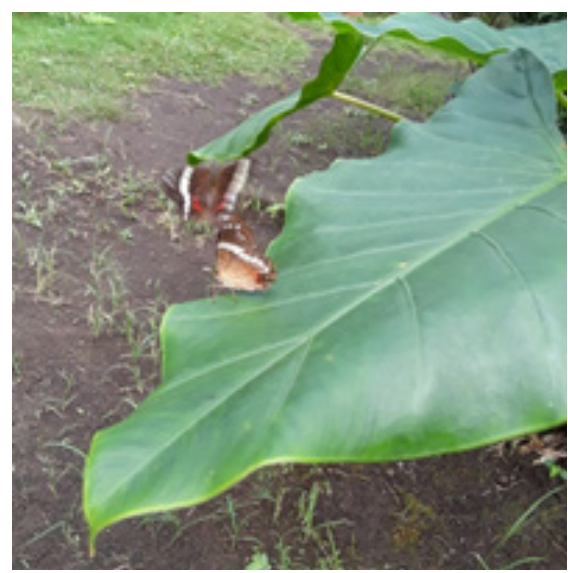

Mariposas que se encuentran en el parque Sur, Isla de Ometepe, 2020 (Foto: Oswlin Potoy)

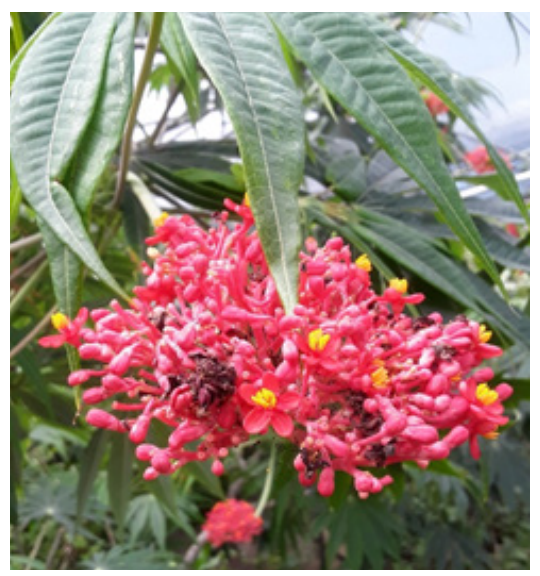

Planta que se encuentra dentro del parque y mariposario Charco Verde, comunidad de San José
de Sur, Isla de Ometepe, 2020 (Foto: Oswlin Potoy). 


\title{
Raíces
}

\section{Testimonios de habitantes de la Isla de Ometepe}

\author{
Etiquetas:
}

E: Entrevistador

X1: Entrevistado

|: Pausa breve

II: Pausa mediana

I: Tono descendente

/: Tono ascendente

:: : Alargamiento de un sonido

Testimonio 1

E: ¿Cuál es la historia que ha escuchado sobre El Charco Verde?

X1: \Sobre el Charco Verde he escuchado que |el Charco verde está encantado| encantado por una| bruja que le decían la Mama Bucha, eh... La mama Bucha tenía un hijo llamado Francisco que le decían Chico largo, se convertía en Chico Largo| era un fantasma || que todo mundo le tenía miedo y nadie se podía acercar al Charco Verde|| cuando la mama Bucha murió quedó en su lugar Francisco| que tomó el poder, hasta que murió.

E: ¿Alguna vez usted visitó la reserva y le sucedió algo fuera de lo normal?

X1: Fui al Charco Verde con mi familia| con un nietecito tenía como unos seis :: como unos ocho años, entramos al Charco verde y mi nieto no quería entrar porque sintió temor y decía: ahí no me da miedo, más sin embargo hicimos el impulso de| de:: meternos e ir a conocer hasta cierto lugar|l. En ese lugar que nosotros fuimos, se sentía:: miedo|, pasábamos un puente de madera, que sentíamos como que se nos tiraba la anaconda, entonces, y se siente ::una soledad| un aire| todo raro. Miré un hombre que estaba sentado en ell en lo último hasta donde llegaba| el ojo| del agua del charco verde, cuando pasamos para adentro estaba sentado, pasamos de regreso y estaba en el mismo lugar, y me dio más miedo porque ya miramos que\| no era algo normal:: |no era algo bueno. 
E: ¿Cuándo usted estaba niña, sus padres le atemorizaron alguna vez con esta leyenda?

X1: Si| porque mi papá siempre nos hablaba del Charco Verde, siempre nos hablaba de la mama Bucha| entonces nosotros teníamos miedo a cerca de lo que él nos hablaba|| y cuando caía la noche| vos sabes, Ometepe| vivíamos en la Loma y ahí era oscuro y siempre teníamos miedo, y nos poníamos a jugar y decíamos: ahí viene la mamá Bucha, no sabiendo quien era la mama Bucha|, podría ser un espanto| pero nunca supimos en ese momento quien era la mama Bucha, pero siempre teníamos ese miedo y yo pues siempre soñaba con tres muchachitos|, tres niños pelones, pero, eran unos niños, unos duendes/, me llevaron y me subieron a un árbol y después no me di cuenta como me bajé.

\section{Entrevistas realizadas}

Aguirre, M. de la C. (2021). Habitante de Ometepe. (O. Potoy, Entrevistador).

\section{Oswlin Potoy Mejía}

Estudiante del cuarto año de la carrera Lengua y Literatura Hispánica de la Universidad Nacional Autónoma de Nicaragua, UNAN- Managua. Ha participado en cursos de creación literaria con escritores nacionales y a nivel centroamericano con la Academia Abecedaria editoras \& estudios culturas, Costa Rica. Sus áreas de interés se relacionan con la Historia, Literatura, Antropología y Religión. Ha escrito cuentos, poemas, y ensayos expuestos en Jornadas educativas y actividades académicas sobre personajes de gran influencia en la Literatura e Historia nicaragüense como Sandino y Rubén Darío, además de grabar un podcast que contiene tres capítulos sobre la vida y obra del Príncipe de las Letras Castellanas. 